\title{
Breast Feeding Remains a Strong Protection against Infant Infections
}

\author{
Shagufta Sohail ${ }^{1}$, Kaneez Fatima $^{1}$, Noshina Riaz' \\ ${ }^{1}$ Assistant Professor, Department of Paediatrics, Yusra Medical and Dental College, Islamabad
}

ABSTRACT

Background: Breast feeding prevents infections in infants. Bottle-fed infants who are partially breast-fed or never breast-fed at all are at higher. The objectives of this study were to record the effect of exclusive breast feeding versus partial and never breast feeding on infections in infants and also to find an association of infection with type of feed, gestation and vaccination status in infants till six months of age.

Material and Methods: A total of 500 Infants were included in this cross-sectional study. Information regarding pattern of feeding and infections was obtained by verbal interview of mother and the questionnaire was filled by the study physician. The outcome evaluated was infections in infants till one year of age. Categorical comparisons were made using chi square test. A ' $p$ ' value $<0.05$ was considered statistically significant.

Results: Out of 500 infants, $59.4 \%$ were males. About $59.6 \%$ were exclusively breast-fed till 6 months of age, $31.2 \%$ were partially breast-fed and $9.2 \%$ were never breast-fed. In exclusively breast-fed group, $29.5 \%$ infants reported infections as compared to $40.4 \%$ in partial breast-fed group and $65.2 \%$ in never breast-fed infants $(P<0.000)$. Similarly, $40.6 \%$ of infants in exclusively breast-fed group, $55.1 \%$ in partial breast feed and $58.7 \%$ in the never breast-fed reported infections in 4-6 months of age, which was statistically significant $(P=0.003)$. There was no significant difference in infection rates among the three study groups in 7-9 $(P=0.192)$ and $10-12$ months $(P=0.42)$ of age.

Conclusions: Exclusive breast feeding till six months of age significantly reduces the risk of infections in infancy.

Key words: Exclusive breast feeding, Infant infections, Partial breast feeding

Authors' Contribution:

${ }^{1-3}$ Conception, synthesis, planning of research and manuscript writing Interpretation, discussion, Active participations in data collection Data analysis.

Cite this article. Sohail S, Fatima K, Riaz N. Breast feeding remains a strong protection against infant infections. J Islamabad Med Dental Coll.2019; 8(4): 203-207. Doi: 10.35787/jimdc.v8i4.351
Correspondence:

Shagufta Sohail

Email: shaguftasohail2009@hotmail.com
Article info:

Received: June 6, 2019

Accepted: November 19, 2019

\section{Introduction}

Breast milk is nature's first gift to the newly born baby. World Health Organization (WHO) recommends breastfeeding within one hour after birth but currently only $50 \%$ of neonates are breast-fed in the first hour of life in the world. 1,2 WHO recommends exclusive breast feeding till six months and it should be continued till two years of age as a part of mixed diet. ${ }^{3}$ However, only $37 \%$ of infants are exclusively breastfed till six months of age in developing countries. ${ }^{4}$ Duration of breast feeding is even shorter in developed countries. There are more chances of morbidity and mortality from different infections in infants who are not breast fed or are partially fed. If babies are breast fed according to global recommendations, 823,000 children could be saved each year. ${ }^{4}$

Breast feeding provides optimal nutrition to the growing infants in initial six months after birth. ${ }^{5}$ It helps in maturation of immune system and prevents infections. ${ }^{6}$ Breast feeding has an immediate protective effect against upper and lower respiratory tract infections, otitis media, diarrhea and urinary tract infection. ${ }^{7}$ Multiple studies in developing countries show that the risk of infections especially respiratory and diarrheal infections is increased with shorter duration of breast feeding. These studies considered different durations of exclusive breast feeding but did not study the duration and exclusiveness of breast 
feeding together. The objectives of this study were to record the effect of exclusive breast feeding versus partial and never breast feeding on infections in infants and also to find an association of infection with type of feed, gestation and vaccination status in infants till six months of age.

\section{Material and Methods}

This was an observational cross-sectional study done in Yusra General Hospital at Pediatrics department from November 2017 till October 2018. Non-Probability convenient sampling technique was used for sample collection. Infants till two years of age reporting to the hospital with their mothers with various complaints were included. WHO calculator was used to calculate sample size of study. At $95 \%$ confidence interval, $5 \%$ absolute precision and anticipated population proportion assumed to be $50 \%$, total sample size calculated was 384 . However, data was collected from 500 subjects. Informed consent was taken from the mother and information regarding type of feeding and infections was obtained by verbal interview and was noted by the principal investigators. ${ }^{6}$ Infants with congenital anomalies, twin deliveries and those attending day care centers were excluded. The study was approved by the Ethics Committee of Yusra Medical and Dental College and Yusra General Hospital.

Mothers were asked about their education status, gestation and mode of delivery of the infant. Type of infant feeding till 6 months of age was categorized as 'exclusive breast-fed' for infants taking only breast milk. 'Partial breast-fed' included infants on breast feed along with formula feed or any other milk and 'never breast-fed' included infants who had not been fed on breast milk at all. Infants whose vaccination was complete according to expanded program of immunization (EPI) were said to be 'fully vaccinated', if they had missed few vaccines were labelled as 'partially vaccinated' and if they had received no vaccine as 'not vaccinated'.

The outcome which was evaluated after different type of feeding was infections in infancy for which medical consultation was taken in first 3 months of life, at 4-6 months, 7-9 months and 10-12 months of age. Data was analyzed using SPSS version 23. Frequencies and percentages were calculated from descriptive variables. Categorical comparisons were made using Chi-square test with a $P$ value $<0.05$ considered statistically significant.

\section{Results}

Of the 500 infants enrolled in the study, 297(59.4\%) infants were male, 433 (86.6\%) were born at full-term and $448(89.6 \%)$ were fully-vaccinated. About $215(43 \%)$ of the mothers were educated up to $10^{\text {th }}$ grade. Table I shows the demographic characteristics of the study population. In this study, 298 (59.6\%) infants were exclusive breast-fed while $156(31.2 \%)$ were partial breast-fed.

Table I: Demographic characteristics of study population

\begin{tabular}{|c|c|c|}
\hline \multicolumn{2}{|l|}{ Variables } & $\mathrm{n}(\%)$ \\
\hline \multirow[t]{2}{*}{ Gender of infant } & Male & $297(59.4)$ \\
\hline & Female & $203(40.6)$ \\
\hline \multirow[t]{5}{*}{ Education of mother } & Illiterate & $21(4.2)$ \\
\hline & Matric & $215(43)$ \\
\hline & Intermediate & $92(18.4)$ \\
\hline & Graduate & $102(20.4)$ \\
\hline & Post graduate & $70(14)$ \\
\hline \multirow[t]{3}{*}{ Gestation } & Pre-term & $44(8.8)$ \\
\hline & Term & $433(86.6)$ \\
\hline & Post-term & $23(4.6)$ \\
\hline \multirow[t]{3}{*}{ Vaccination status of infant } & Fully & $448(89.6)$ \\
\hline & Partially & $44(8.8)$ \\
\hline & None & $8(1.6)$ \\
\hline
\end{tabular}

In exclusively breast-fed group, $29.5 \%$ infants reported infections compared with $40.4 \%$ in partial breast-fed group and $65.2 \%$ in never breast-fed infants in first 3 months. This difference was statistically significant with ' $P$ ' value of 0.000 . Similar high protection against infections was noticed in the exclusive breast-fed group during 4-6 months of age (Table II). Although infection rates increased with increasing age of infants, they were considerably less in exclusive breast-fed group. Our study showed that infants who were never breast fed reported highest infections during first 3 months of life $(65.2 \%)$ and that pattern remained stable in the subsequent months of age with little decline (Table II). $P$ values in Table II suggest that results were significant for exclusive and partial breast-fed group for all comparison from baseline indicating more children were likely to report infection during subsequent months of age. While the data showed 


\begin{tabular}{|c|c|c|c|c|c|}
\hline \multicolumn{6}{|c|}{ Table II: Association of type of feed with infection and age of infant } \\
\hline & Infection & $\begin{array}{c}0-3 \text { months } \\
a\end{array}$ & $\begin{array}{c}\text { 4-6 months } \\
\text { b }\end{array}$ & $\begin{array}{c}\text { 7-9 months } \\
\text { C }\end{array}$ & $\begin{array}{c}10-12 \text { months } \\
\text { d }\end{array}$ \\
\hline \multirow[t]{2}{*}{ Exclusive } & No & $210(70.5)$ & $177(59.4)$ & $147(49.3)$ & $112(37.6)$ \\
\hline & Yes & $88(29.5)$ & 121(40.6) & 151(50.7) & 186(62.4) \\
\hline \multirow[t]{2}{*}{ Partial } & No & $93(59.6)$ & $70(44.9)$ & $63(40.4)$ & $59(37.8)$ \\
\hline & Yes & $63(40.4)$ & $86(55.1)$ & 93(59.6) & $97(62.2)$ \\
\hline \multirow[t]{2}{*}{ None } & No & $16(34.8)$ & $19(41.3)$ & $21(45.7)$ & $22(47.8)$ \\
\hline & Yes & $30(65.2)$ & $27(58.7)$ & $25(54.3)$ & $24(52.2)$ \\
\hline \multirow[t]{2}{*}{$P$-value } & Chi-square & $0.000^{*}$ & $0.003^{*}$ & 0.192 & 0.420 \\
\hline & $\begin{array}{l}\text { Post hoc hypothesis } \\
\text { test }\end{array}$ & $\begin{array}{l}\text { EBF. } 0.0001^{*} \\
\text { Partial } 0.193 \\
\text { None: } 0.000\end{array}$ & $\begin{array}{c}\text { EBF } 0.00{ }^{*} \\
\text { Partial } 0.0124 \\
\text { None } 0.0891\end{array}$ & & \\
\hline
\end{tabular}

\begin{tabular}{|c|c|c|c|c|}
\hline \multicolumn{5}{|c|}{ Table III: Association of infection with type of feed, gestation and vaccination in infants up to 3 months of age } \\
\hline & & Odds ratio & $95 \%$ Confidence Interval & $P$ value \\
\hline \multirow[t]{3}{*}{ Type of feed } & EBF & Reference & & \\
\hline & EBF versus partial breast-fed & 1.698 & $1.12-2.57$ & 0.012 \\
\hline & EBF versus no breast-fed & 4.463 & $2.29-8.69$ & $0.000^{*}$ \\
\hline \multirow[t]{3}{*}{ Gestation } & Preterm & Reference & & \\
\hline & Pre term versus term & 0.358 & $0.18-68$ & $0.002^{*}$ \\
\hline & Preterm versus post term & 0.609 & $0.22-1.72$ & 0.351 \\
\hline \multirow[t]{3}{*}{ Vaccination } & Fully vaccinated & Reference & & \\
\hline & Fully vaccinated versus partial vaccinated & 1.283 & $0.668-2.468$ & 0.453 \\
\hline & Fully vaccinated versus none & 3.271 & $0.727-14.708$ & 0.122 \\
\hline
\end{tabular}

${ }^{*} P<0.05$ considered statistically significant

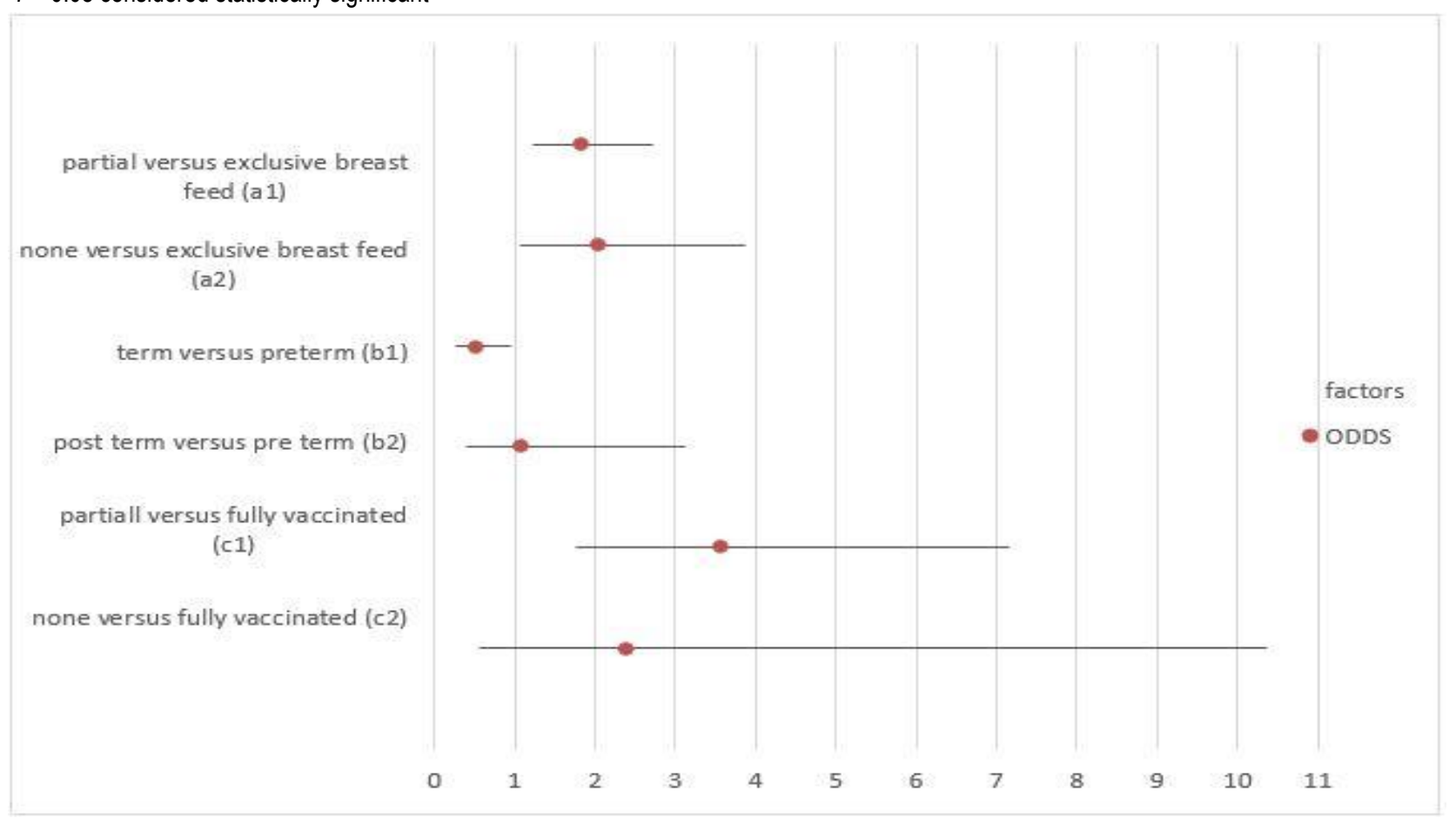

Figure 1. Association of infection with type of feed, gestation and vaccination in 4-6 months of age.

Odds ratio plot along with $95 \%$ confidence interval from binary logistic regression analysis

$P$ values a1 $=0.003, \mathrm{a} 2=0.031, \mathrm{~b} 1=0.039 \mathrm{~b} 2=0.874, \mathrm{c} 1=0.000 \mathrm{c} 2=0.244$ 
that for never breast-fed group, subsequent comparisons from baseline were not significant. The results of linear regression analysis showed that during first 6 months, breast feeding offered greater protection against infections during the first three months. The odds of having infection were $1.698(95 \% \mathrm{Cl} 1.12---2.57$; $P$ value 0.012) times higher in partial breast-fed as compared to exclusive breast-fed infants. Similar higher odds (OR 4.463; 95\% Cl 2.29-28.69; $P$ value 0.000 ) of infection were seen for never breast-fed group versus exclusively breast-fed group, when other variables entered in the model were held constant (Table III).

From 4-6 months of age, the results showed higher odds for infection (OR 1.827; 95\% Cl 1.22 --- 2.72; $P$ value 0.003 ) for partial breast-fed infants versus exclusive breast-fed infants and similar higher odds of infection (OR 2.036; 95\% Cl 1.068-3.88; $P$ value 0.031) in never breast-fed group compared with exclusive breast-fed group (Table III). This shows that during first 6 months of life breast feeding offer greater protection against infections.

\section{Discussion}

This study done locally in a Pakistani community emphasizes the effectiveness of breast feeding against infections in infancy. Exclusive breast feeding for six months prevents infections in infants. Even infants who are breast fed partially showed the protective effect by having lesser infections as compared to those who are never breast fed.

The results of the study are similar to various studies done in different regions which have documented beneficial effect of breast feeding against common infections in infancy. ${ }^{8,9}$ In a cohort study done in United Kingdom, Quigley et al. concluded that there is an increased risk of infection in infants who are exclusively breast fed for less than four months or for four to six months or those who stop breast feeding by six months of age. ${ }^{8}$ Similarly a study from Bangladesh showed the beneficial effect of exclusive breast feeding for six months against infections. ${ }^{9}$ They suggested that exclusive breast feeding for six months prevents infants from fever, acute respiratory infections and diarrhea. ${ }^{9}$

Encouraging breast feeding exclusively for six months is an effective and inexpensive way for prevention of infections in infancy. It ultimately decreases the number of hospital visits and admissions. A Scottish cohort study by Ajetunmobi at el reported the protective effect of breast feeding in infants with the conclusion that there is a higher risk of hospital admissions for gastroenteritis and respiratory tract infections in formula-fed infants. ${ }^{10}$ Similar results were seen is a study done in a rural area in India, which found a high incidence of diarrhea in non-breast-fed babies. ${ }^{11}$

Breast feeding for six months or more was significantly associated with decreased risk of lower respiratory tract infections in preschool children till four years of age.12 Protective effect of breast feeding against infections is not limited to infancy. Its beneficial effects beyond infancy against respiratory tract infections were observed in The Generation R study, which concluded that exclusive breast feeding for six months or more was significantly associated with decreased risk of lower respiratory tract infections in preschool children till four years of age. ${ }^{12}$

Prolonged exclusive breast feeding for 6 months has a significant beneficial effect against infections especially in low to middle income countries. Only $37 \%$ of infants younger than six months are breast fed exclusively in middle to low income countries. ${ }^{4}$ Exclusive breast feeding for 6 months was observed in $59.6 \%$ of our study population as compared to $41.5 \%$ in a study done in Faisalabad in working mothers, $66 \%$ in a study from Ghana and only $9 \%$ in United States, showing a falling trend of exclusive breastfeeding in industrialized world. ${ }^{13-}$ 15 Two main factors which significantly predispose infants to infection are preterm delivery and lack of immunization. Most of the late preterm infants in this study were exclusively breast fed by their mothers till six months of age and hence were protected against common infections in infancy by favorable effects of breast milk.

Similarly, immunization has protective role against respiratory and diarrheal infections. Majority of infants despite their different feeding patterns were fully 
vaccinated according to EPI schedule in this study conferring the protective effect of vaccination.

The main limitation of this study was that the information included was obtained through interview of the mother, making it subjective and biased.

\section{Conclusion}

Exclusive breast feeding till six months significantly reduces the risk of infection in infancy.

\section{References}

1. Phukan D, Ranjan M, Dwidevi LK. Impact of timing of breastfeeding initiation on neonatal mortality in India. Int Breastfeed J. 2018; 13: 27. Doi: 10.1186/s13006018-0162-0

2. Ebmond K, Newton S, Hurt L, Shannon CS, Kirkwood BR, Taneja $S$, et al. Timing of initiation, patterns of breast feeding, and infant survival: prospective analysis of pooled data from three randomized trials. Lancet Glob Health. 2016; 4(4): e266-75. Doi: 10.1016/S2214-109X(16)00040-1

3. WHO. The World Health Organization's infant feeding recommendation, World Health Organization. 2016. http://www.who.int/nutrition/topics/infantfeeding recommendation/en/

4. Victora GG, Bahl R, Barros AJ, Franca GV, Horton S, Krasevec J, Murch S, Sankar MJ, Walker N, Rollins NC. Breast feeding in the $21^{\text {st }}$ century: epidemiology, mechanisms, and lifelong effect .Lancet. 2016; 387(10017): $\quad 475-90$. Doi: 10.1016/S01406736(15)01024-7.

5. Martin CR, Ling PR, Blackburn GL. Review of infant feeding: key features of breast milk and infant formula. Nutrients. 2016; 8(5): E279. Doi: 10.3390/nu8050279

6. Butt CA, Hedderley DI, Herath TD, Paturi G, GlynJones $\mathrm{S}$, Wiens $\mathrm{F}$ et al. Human milk composition and Dietry intakes of breast-feeding women of different ethnicity from the manawatu-wanganui Region of New Zealand. Nutrients. 2018; 10(9): E1231.Doi: 10.3390/nu10091231.

7. Frank NM, Lynch KF, Uusitalo U, Yang J, Lönnrot M, Virtanen SM et al. The relationship between breastfeeding and reported respiratory and gastrointestinal infection in young children. BMC
Pediatr. 2019; 19(1): 339. Doi: 10.1186/s12887-0191693-2

8. Quigley MA, Carson C, Sacker A, Kelly Y. Exclusive Breastfeeding duration and infant infection. Eur $\mathrm{J}$ Clin Nutr. 2016; 70(12):1420-27. Doi: 10.1038/ejcn.2016.135

9. Khan MN, Islam MM. Effect of exclusive breastfeeding on selected adverse health and nutritional outcomes: a nationally representative study. BMC Public Health. 2017; 17(1): 889. Doi: 10.1186/s12889-017-4913-4

10. Ajetunmobi OM, Whyte B, Chalmers J, Tappin DM, Wolfson $L$, Fleming $M$ et al. Breastfeeding is associated with reduced childhood hospitalization: evidence from a Scottish Birth Cohort (1997-2009). J Pediatr. 2015; 166: 620-5. Doi: 10.1016/j.jpeds.2014.11.013

11. Biswas A, Mandal AK. A study on association between breast feeding and its protective role against diarrhea in under five children in a rural block of West Bengal, India. Int J Community Med Public Health 2016; 3(9): 2499-503. Doi: 10.18203/23946040.ijcmph20163060

12. Tromp I, Kiefte-de Jong J, Raat $H$, Jaddoe V, Franco $O$, Hofman $A$ et al. Breastfeeding and risk of respiratory tract infections after infancy: The Generation R Study. PLoS One. 2017; 12(2): e0172763. Doi: 10.1371/journal.pone. 0172763

13. Sabin A, Manzur F, Adil S. Exclusive breastfeeding practices in working women of Pakistan: A cross sectional study. Pak J Med Sci. 2017; 33(5): 11481155. Doi: $10.12669 /$ pjms.335.12827

14. Asare BY, Preko JV, Baafi D, Dwumfour-Asare B. Breastfeeding practices and determinants of exclusive breastfeeding in a cross-sectional study at a child welfare clinic in Tema Manhean, Ghana. Int Breast feed J. 2018; 13: 12. Doi: 10.1186/s13006018-0156-y

15. Nnene-Agumadu UH, Racine EF, Laditka SB, Coffman MJ. Association between perceived value of exclusive breastfeeding among pregnant women in the United States and exclusive breast feeding to three and six months postpartum: a prospective study. Int Breast feed J. 2016; 11: 8. Doi: 10.1186/s13006-016-0065-x 
